AperTO - Archivio Istituzionale Open Access dell'Università di Torino

\title{
De-alloying of rapidly solidified amorphous and crystalline alloys
}

\section{This is the author's manuscript}

Original Citation:

Availability:

This version is available http://hdl.handle.net/2318/90933

since 2015-12-30T16:09:00Z

Published version:

DOI:10.1016/j.jallcom.2010.12.209

Terms of use:

Open Access

Anyone can freely access the full text of works made available as "Open Access". Works made available under a Creative Commons license can be used according to the terms and conditions of said license. Use of all other works requires consent of the right holder (author or publisher) if not exempted from copyright protection by the applicable law. 


\section{(3) \\ UNIVERSITÀ DEGLI STUDI DI TORINO}

This Accepted Author Manuscript (AAM) is copyrighted and published by Elsevier. It is posted here by agreement between Elsevier and the University of Turin. Changes resulting from the publishing process - such as editing, corrections, structural formatting, and other quality control mechanisms - may not be reflected in this version of the text. The definitive version of the text was subsequently published in Journal of Alloys and Compounds 509S (2011) S8-S12, Available online 4 January 2011, digital object identifier link: http://dx. doi:10.1016/j.jallcom.2010.12.209

You may download, copy and otherwise use the AAM for non-commercial purposes provided that your license is limited by the following restrictions:

(1) You may use this AAM for non-commercial purposes only under the terms of the CC-BY-NC-ND license.

(2) The integrity of the work and identification of the author, copyright owner, and publisher must be preserved in any copy.

(3) You must attribute this AAM in the following format: Creative Commons BY-NC-ND license (http://creativecommons.org/licenses/by-nc-nd/4.0/deed.en), [+ Digital Object Identifier link http://dx. doi:10.1016/j.jallcom.2010.12.209 to the published journal article on Elsevier's ScienceDirect ${ }^{\circledR}$ platform] 


\title{
De-alloying of Rapidly Solidified Amorphous and Crystalline Alloys
}

Livio Battezzati, Federico Scaglione

Dipartimento di Chimica IFM e Centro NIS, Università di Torino, Torino, Italy. livio.battezzati@unito.it $\quad$ federico.scaglione@unito.it

\begin{abstract}
De-alloying occurs when a less noble metal is selectively removed from an alloy either by chemical or electrochemical means. Under appropriate experimental conditions and for suitable alloy composition, the resulting material is constituted by crystalline ligaments rich in the noble element and pores. The literature reports a substantial amount of information on de-alloying crystalline homogeneous solid solutions, mostly based on noble metals, whereas the process has been attempted in a limited number of cases with amorphous alloys. The latter case is reviewed here and new results are given for a Au-based metallic glass evidencing the role of the critical potential and surface roughness.

It can be also of interest to remove selectively from the alloy a single phase leaving a sieve-like matrix. which might itself be porous. The size of the pores and of the remaining solid can be tailored by controlling the grain size of the phases. Examples are given for this second process and experiments are reported on successful selective etching of rapidly solidified Fe-C eutectics.
\end{abstract}

Keywords: de-alloying, amorphous alloys, rapidly solidified eutectics, corrosion.

\section{Introduction}

Porous metals can be made by selective removal of a phase or an element from a bulk alloy by chemical or electrochemical means. The topic has recently gained interest for tailoring nanoporous metallic materials aiming at improved properties in various field such as catalysis, sensors, hydrogen storage, molecular sieves. The recent literature reports significant examples which can be 
classified according to the initial microstructure of the alloy. Dissolution of a phase in a two phase material gives porosity of various sizes, starting typically from the micron range. Examples include Ni-base superalloys [1, 2], $\mathrm{Cu}-\mathrm{Zr}$ [3], Ti-Al [4]. In these an equilibrium phase is etched away after suitable thermal or mechanical processing aimed at tailoring its size. Instead, the non-equilibrium demixing of the melt before solidification has been exploited to create phase dispersions in $\mathrm{Cu}-\mathrm{Co}$ and $\mathrm{Cu}-\mathrm{Fe}$ alloys $[5,6]$ before etching. In some cases, the phase constitution of the material involves two solutions or a solution and a compound: the phase containing the less noble component is totally removed and the other phase originates a porous structure because of dealloying as in $\mathrm{Au}-\mathrm{Al}$, made of a $\mathrm{Au}$ rich solid solution and an $\mathrm{Al}_{2} \mathrm{Au}$ phase. The material has then a bimodal distribution of pore sizes [13]. De-alloying of an element from crystalline homogeneous solid solutions, mostly based on noble metals, has received much attention with both experiments and models to elucidate the structure and the mechanism of formation of the pore-ligament network of the remaining noble element; for a review see [7]. This process provides the finest pore size, in the nanometre range, as shown for $\mathrm{Au}-\mathrm{Ag}$ [7], $\mathrm{Au}-\mathrm{Cu}$ [7], $\mathrm{Au}-\mathrm{Sn}$ [8], $\mathrm{Cu}-\mathrm{Mn}$ [9] alloys. De-alloying of homogeneous amorphous alloys as well as of phase separated amorphous phases, has been attempted in a number of cases with success [10-12]. multicomponent, removal of elements bring composition outside the glass-forming range, nucleation

The removal of a single phase from an alloys implies two steps: the design and production of a suitable microstructure and the careful use of etching methods, e. g. of Pourbaix diagrams for electrochemical techniques [1-7]. For obtaining porous structures by de-alloying of an element from a homogeneous solution, a substantial difference in electrochemical potential between alloy components is needed. It has then been shown that a critical potential exists for the morphology of corrosion as well as a "parting limit", i.e. a limiting content of the most noble element, usually less than that of the less noble one. Finally, the mechanisms of crystal reconstruction is based on surface and volume diffusion of the noble species or even their re-deposition from the electrolyte [2, 1417]. 
In this work the selective dissolution of two alloys referring to the different cases just made is described. A two-phase Fe-C alloy having a peculiar microstructure obtained by rapid solidification is first treated. Then, the electrochemical etching of an amorphous Au-based alloy containing embedded crystals, mostly on the surface, is reported. Here, the role of the underlying amorphous structure, of the surface roughness and crystallisation must be considered in addition to the conventional electrochemical parameters [18].

\section{Experimental}

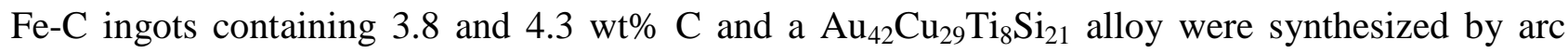
melting elements of the following purity: $99.98 \% \mathrm{Fe}, 99.999 \% \mathrm{C}$ (electronic grade), $99.99 \% \mathrm{Au}$, 99.99\% $\mathrm{Cu}, 99,9995 \% \mathrm{Si}, 99.99 \% \mathrm{Ti}$, after evacuating and purging the furnace several times with high purity Ar and using lumps of $\mathrm{Zr}$ and $\mathrm{Ti}$ as getters. Parts of the crushed ingots were melt spun from a silica crucible onto a hardened $\mathrm{Cu}$ wheel under high purity Ar, obtaining ribbons $2 \mathrm{~mm}$ wide and 25-30 $\mu \mathrm{m}$ thick.

For electrochemical de-alloying, samples have been used as working electrode in a cell composed of a Standard Calomel reference electrode (SCE) and a Pt counter electrode in a Potentiostat/Galvanostat Model 7050, Amel Instruments.

The Fe-C alloys were etched in $14 \mathrm{M} \mathrm{NaOH}$ and $2 \mathrm{~V}$, conditions suited to remove the cementite phase. The critical potential for de-alloying $\mathrm{Au}_{42} \mathrm{Cu}_{29} \mathrm{Ti}_{8} \mathrm{Si}_{21}$ was determined by performing anodic polarization experiments as $1,75 \mathrm{~V}$. Potentiostatic and galvanostatic methods were employed with an electrolyte made of a $0.1 \mathrm{M} \mathrm{HNO}_{3}$ aqueous solution; in the former, samples have been etched for 20 hours at 1,80-1,90 V (versus SCE electrode), in the latter, samples have been etched at $15 \mathrm{~mA}$ for 6 hours. During processing, the potential and current fluctuated around the average of tens of $\mu \mathrm{V}$ and units of $\mathrm{mA}$, respectively. 
Samples have been analysed before and after etching using X-ray diffraction (XRD) in BraggBrentano geometry with monochromatic $\mathrm{Cu} \mathrm{K} \square$ radiation, scanning electron microscopy (SEM), Energy Dispersive X-ray Spectroscopy (EDS) (calibrated with a pure Co sample)

\section{Results and Discussion}

\subsection{Fe-C eutectics}

Microstructural studies of binary cast irons produced with elements of high purity, have shown that the formation of the expected conventional eutectics can be kinetically suppressed by solidification at the rates achievable in the melt spinning process. A mixture of metastable cementite, slightly offstoichiometry, and supersaturated ferrite is obtained directly from the liquid in eutectic form with the phase proportion of $61 \mathrm{vol} \%$ and 39 vol\% respectively [19]. Phase diagram calculation confirmed that the composition of the metastable eutectic is $3.8 \mathrm{wt} \% \mathrm{C}$. A cross section of a ribbon of this $\mathrm{C}$ content is reported in Fig. 1 showing the completely eutectic microstructure. Only in thicker ribbons a transition from the microstructure of Fig. 1 to ledeburite was found.

Conditions for electrochemical etching were chosen to obtain the highest current efficiency which corresponds to oxidising the iron present in carbides to ferrate ions and carbon to carbonate ions [20]. This allows selective removal of cementite from the alloy. Fig. 2 shows the former air side of the ribbon which displays now widespread porosity within a Fe network. The size of the pores is on average of the order of two microns. They clearly extend into the inner part of the ribbon. Complete etching was achieved after 70 minutes. Other samples which remained for different times at potential in excess of $1 \mathrm{~V}$ were fully etched as well. The resulting material was rather loose so it was not possible to embed it in resin and polish to show a cross section. However, it was strong enough for XRD which demonstrated it is constituted entirely by Fe. The Fe is dissolved in the same conditions although definitely more slowly being protected to some extent by a passivating 
oxide film [20]. The etching must therefore be terminated at a given stage to avoid further extensive Fe corrosion.

The same electrochemical procedure was applied to slices of various thickness of an arc melted ingot of $\mathrm{Fe}-4.3 \% \mathrm{C}$ which displayed fine alternate lamellae of ferrite and cementite after solidification. The cementite was removed and the material displayed pores one to two microns wide and of various length up to tens of microns (Fig. 3). The selective etching could be prolonged for various hours to obtain thick porous iron. Fig. 4 shows a view in lateral perspective of a foil, originally $80 \mu \mathrm{m}$ thick, which appears fully etched after about 18 hours at $2 \mathrm{~V}$. The ferrite lamellae only remain.

It is, therefore, concluded that porous patterns of different size and shape can be obtained on account of the starting alloy microstructure.

\subsection{Au based amorphous alloy}

The Au-Si system is the early prototype of a metallic glass-former by rapid solidification [21]. More recently, bulk metallic glasses have been obtained with atomic content $\mathrm{Au}_{49} \mathrm{Ag}_{5.5} \mathrm{Pd}_{2.3} \mathrm{Cu}_{26.9} \mathrm{Si}_{16.3}$ [22], a composition clearly related to the $\mathrm{Au}-\mathrm{Cu}-\mathrm{Si}$ ternary eutectic. It has also been shown that the addition of $\mathrm{Ti}$, having a negative heat of mixing with $\mathrm{Au}, \mathrm{Cu}$ and $\mathrm{Si}$, improves the glass forming ability of the ternary system, although the resulting alloy is not a bulk glass-former [23]. Among the compositions now available, $\mathrm{Au}_{42} \mathrm{Cu}_{29} \mathrm{Ti}_{8} \mathrm{Si}_{21}$ is below, but close to the parting limit of $\mathrm{Au}$ content for de-alloying. Melt spun ribbons display diverse microstructures from the amorphous wheel side to the air side where quenched-in crystals are found. These belong to a metastable cubic phase, $\mathrm{Cu}_{15} \mathrm{Si}_{4}$ type which was identified in XRD patterns by comparison with other rapidly quenched ribbons of $\mathrm{Au}_{37.5} \mathrm{Cu}_{37.5} \mathrm{Si}_{25}$ composition $[23,24]$. These crystals are quickly removed by electrochemical etching as shown by the disappearance of their reflections from the diffraction pattern leaving an incipient porosity of micrometer size on the ribbon surface. With prolonged 
etching at different potential above the critical one, XRD patterns show that gold rich crystals were obtained on both sides of the ribbon surfaces. Their lattice constant corresponds to that of pure gold within the data scatter [25]. SEM images of the air-side of the ribbon, show, in addition to the microporosity due to the removal of the crystalline phase, a finer porosity found in between particles of pure Au connected to each other (Fig. 5). Similar microstructure is found on the wheelside where the general morphology of gold appears related to the pre-existing roughness of the ribbon surface with longitudinal hillocks and isolated channels (Fig. 6). Galvanostatic experiments provided similar morphology of gold [25].

Crystals and porosity displayed different morphology as a function of applied potential. With potential just above the critical value (e. g. $1.80 \mathrm{~V}$ ), the appearance of the surfaces is more patchy. Some areas are close in morphology to those just described, whereas others contain gold of different shapes. This is more evident on the wheel side as shown in Figs. 7 to 9. The surface displays corrosion cracks and island of Au (Fig. 7). These are more clearly seen in the magnified image of Fig. 8. Cracks can be associated to stress corrosion and to the misfit and volume reduction between the de-alloyed layers and the underlying alloy. Au particles appear deposited on top of the islands. A closer inspection of some of them reveals that they are layered instead of porous (Fig. 9). This is clearly indicative of a different growth mechanism with respect to the previous ones (Figs. 5 and 6). The mechanism of formation of Au crystals must involve a first stage, common to all cases shown here, in which nucleation of crystals occurs very likely heterogeneously on emerging asperities, contrary to de-alloying of crystalline alloys which are composed already of a single face-centered cubic phase. Then, the microstructure of Figs. 5 and 6 made of three dimensional aggregates of gold particles implies surface diffusion of gold when the less noble elements are dissolved. Volume diffusion of Au to the surface could also be invoked, but it is less likely to be effective: in fact, it should cause the formation of crystallization products of the alloy of which no evidence was ever encountered. Instead, the morphology of Figs. 7 to 9 is compatible with local passivation due to 
noble element layers and elemental re-deposition from the electrolyte possibly because of fluctuations of the potential around the critical value [26].

Microanalysis has been performed on both sides of uniform areas of the de-alloyed ribbons showing surface enrichment in gold and depletion in copper while the titanium and silicon percentage was on average decreased less. This results are not in contrast with the XRD results that shows reflections of pure gold after de-alloying: microanalysis data give an average composition between the dealloyed layer, made of pure gold, and the layers below that have not been etched yet. Elemental maps and fine spot EDS analyses showed enrichment of Si and $\mathrm{Ti}$ in the pores accompanied by higher Oxygen signal. A current density of the order of tens of $\mathrm{mA} / \mathrm{cm}^{2}$ was recorded in different experiments. It then decreased progressively as a function of time becoming almost halved after about 50 minutes remaining then substantially constant during the etching time (20 hours). This passivating effect is likely due to both surface gold enrichment and progressive coverage and to enrichment in Si and Ti possibly as oxides in the pores.

Having verified the feasibility of de-alloying of amorphous metallic phases, the mechanism at atomic level is not disclosed, however, and would need detailed examination of the early stages of the process.

\section{Conclusions}

The present work shows that porous patterns of different size and shape can be obtained on account of the starting alloy microstructure in $\mathrm{Fe}-\mathrm{C}$ eutectics providing a cheap mean to obtain materials for catalysis and sieving.

De-alloying of a partially crystalline/amorphous alloy has been performed obtaining porosity of different size. Porous gold networks have been obtained from crystalline alloys in many instances [7-9] containing often finer pores, i. e. in the tens of nanometre range, than those shown in Figs. 5 to

9. The larger Au crystals obtained here can be related to the alloy composition close to the parting 
limit for de-alloying although necessary for glass formation. The role of the initial amorphous structure does not appear decisive. On removing the less noble components, nucleation of gold crystals must be very quick, being facilitated by local heterogeneity and the apparent fast surface diffusion. Using glassy alloys for de-alloying could, however, be interesting to obtain a starting single phase in cases when no crystalline homogeneous phase can be obtained and to promote patterns by controlled crystallisation.

\section{Acknowledgements}

Work performed for "Progetto D23, Bando Regionale Ricerca Scientifica Applicata 2004". Fondazione S. Paolo is acknowledged for support to CdE NIS. 


\section{References}

[1] J. Rösler, D. Mukherji, Adv. Eng. Mater., 5 (12) (2003) 916-918.

[2] Y. N. Li, Z. P. Xi, X. T. Kang, H. P. Tang, W. Y. Zhang, J. Zhang, G. Z. Li, Intermetallics, 17 (2009) 1065-1069.

[3] H.-B. Lu, Y. Li, F-H. Wang, Scripta Mater., 56 (2007) 165-168.

[4] Y. Koizumi, A. Sugihare, H. Tsuchiya, Y. Minamino, S. Fujimoto, H. Yasuda, M. Yoshiya, Acta Mater., 58 (2010) 2876-2886.

[5] L. Battezzati, S. Curiotto, E. Johnson, N. H. Pryds, Mater. Sci. and Eng. A 449-451 (2007) 711.

[6] B. J. Park, Y. M. Chen, T. Ohkubo, Intermetallics, 17 (2009) 958-961.

[7] J. Erlebacher and R. Seshadri eds, Hard Materials with tunable Porosity, MRS Bulletin, 34(8) (2009) 561-566.

[8] S. Hu, W. Huang, Z. Li, Mater. Lett., 64 (2010) 1257-1260.

[9] J. R. Hayes, A. M. Hodge, J. Biener, A. V. Hamza, K. Sieradzi, J. Mater. Res., 21 (2006) 2611 2616.

[10] J. Yu, Y. Ding, C. Xu, A. Inoue, T. Sakurai and M. Chen, Chem. Mater., 20 (2008) 4548-4550.

[11] H. Abe, K. Sato, H. Nishikawa, T. Takemoto, M. Fukuhara and A. Inoue, Materials Trans., 50 (2009) 1255-1258.

[12] J. Jayarai, J. M. Park, P. F. Gostin, E. Fleury, A. Gebert, L. Schultz, Intermetallics, 17 (2009) 1120-1123.

[13] Z.-H. Zhang, Y. Wang, Z. Qi, C. Somsen, X.-G. Wang, C.-C. Zhao, J. Mater. Chem., 19 (2009) 6042-6050.

[14] J. Erlebacher, M. J. Aziz, A. Karma, N. Dimitov, K. Sieradzki, Nature, 410 (2001) 450-453

[15] M. Stratmann and M. Rohwerder, Nature, 410 (2001) 420-423.

[16] K. Sieradzki, N. Dimitov, D. Movrin, C. McCall, N. Vasiljievic, J. Erlebacher, J. Electrochem. Soc., 149 (2002) B370-B377.

[17] J. Erlebacher, J. Electrochem. Soc., 151 (2004) C614-C626.

[18] F. Scaglione, A. Gebert, L. Battezzati, submitted.

[19] L. Battezzati, M. Baricco, S. Curiotto, Acta Mater. 53 (2005) 1849-1856.

[20] K. Bouzek, H. Bergmann, Corros. Sci. 41 (1999) 2113-2128.

[21] W. Klement jr., R. H. Willens, P. Duwez, Nature, 187 (1960) 869.

[22] J. Schoers, B. Lohwongwatana, W. L. Johnson, A. Peker, Appl. Phys. Lett., 87 (2005) 061912.

[23] G. Fiore, L. Battezzati, Rev. Adv. Mater. Sci., 18 (2008) 190-192.

[24] G. Fiore, I. Ichim, L. Battezzati, J. of Physics: Conf. Series, 144 (2009) 012039.

[25] F. Scaglione, A. Gebert, L. Battezzati, submitted.

[26] K. Wagner, S. R. Brancovic, N. Dimitrov, K. Sieradzki, J. Electrochem. Soc., 144 (1997) 3545-3555. 


\section{Figure Captions}

Fig. 1. SEM image (secondary electrons) of a cross section of as-quenched $3.8 \mathrm{wt} \% \mathrm{C}$ ribbon.

Fig. 1

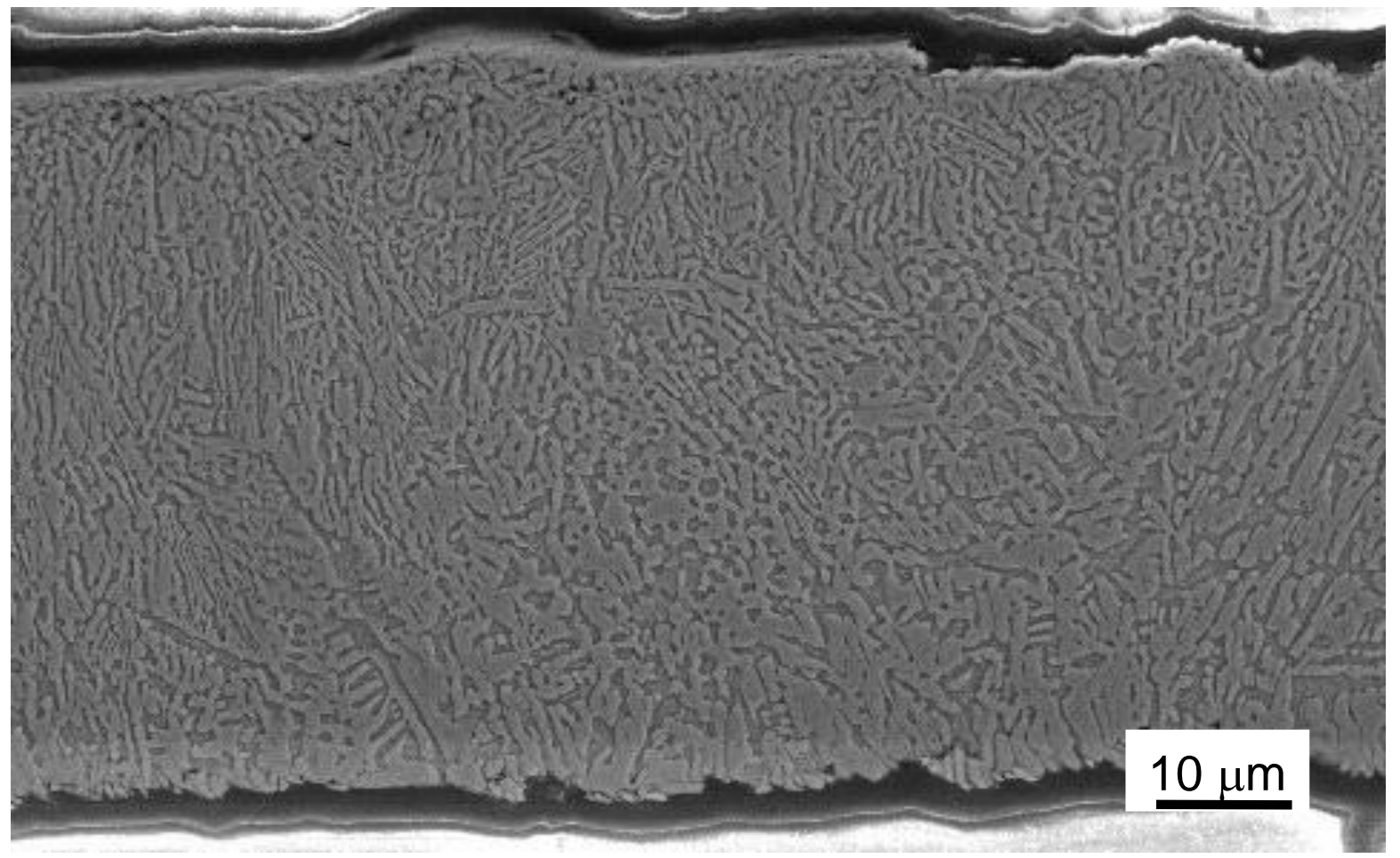

Fig. 2. SEM image (secondary electrons) of as-quenched $3.8 \mathrm{wt} \% \mathrm{C}$ ribbon after electrochemical etching to remove cementite. 
Fig. 2

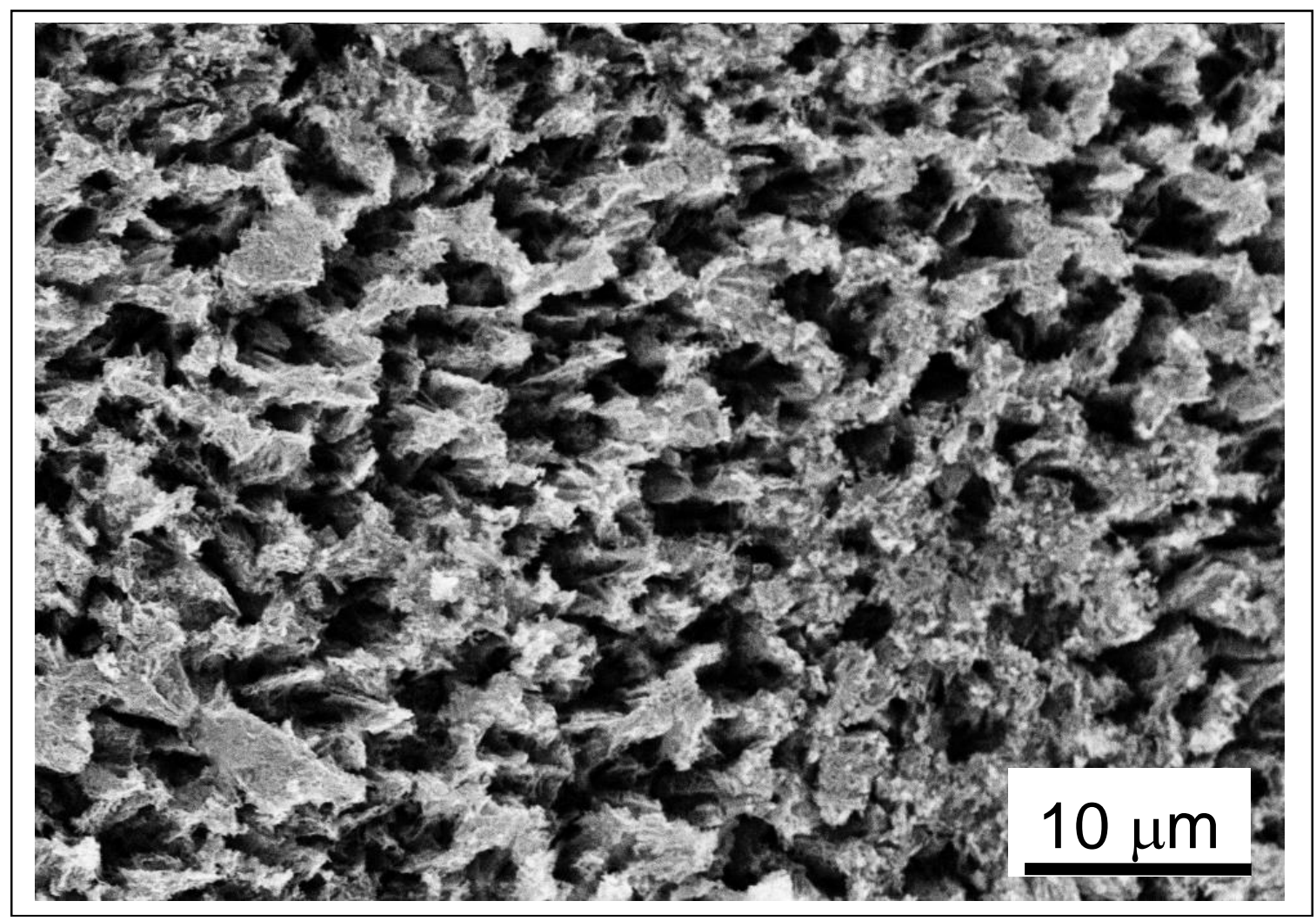

Fig. 3. SEM image (secondary electrons) of as-solidified $4.3 \mathrm{wt} \% \mathrm{C}$ cast iron after electrochemical etching to remove cementite. 
Fig. 3

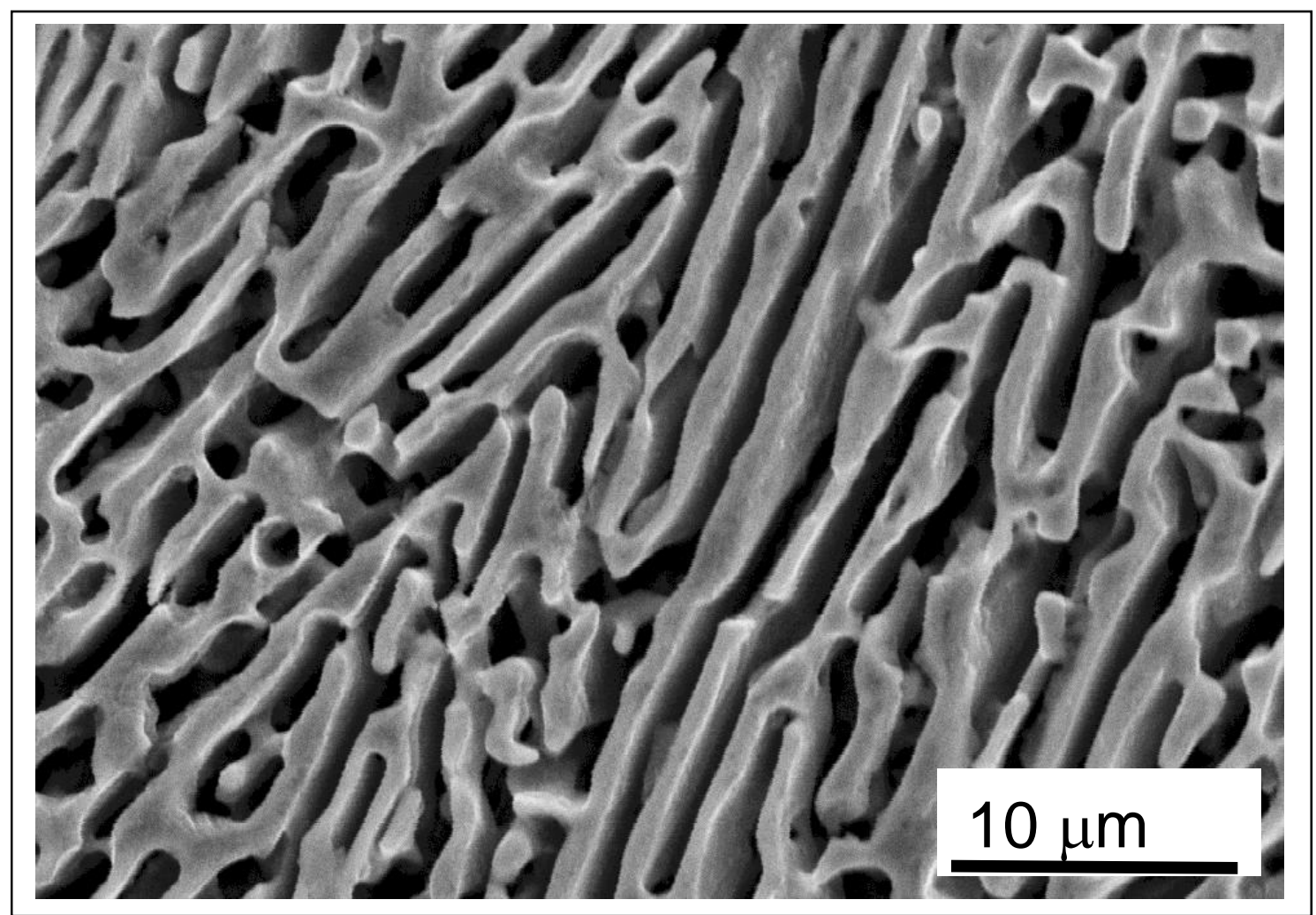

Fig. 4. SEM image (secondary electrons) of as-solidified $4.3 \mathrm{wt} \% \mathrm{C}$ cast iron after prolonged

electrochemical etching to remove cementite. Left: perspective view of a foil originally $80 \mu \mathrm{m}$ thick. Right: magnification of ferrite lamellae.

Fig. 4

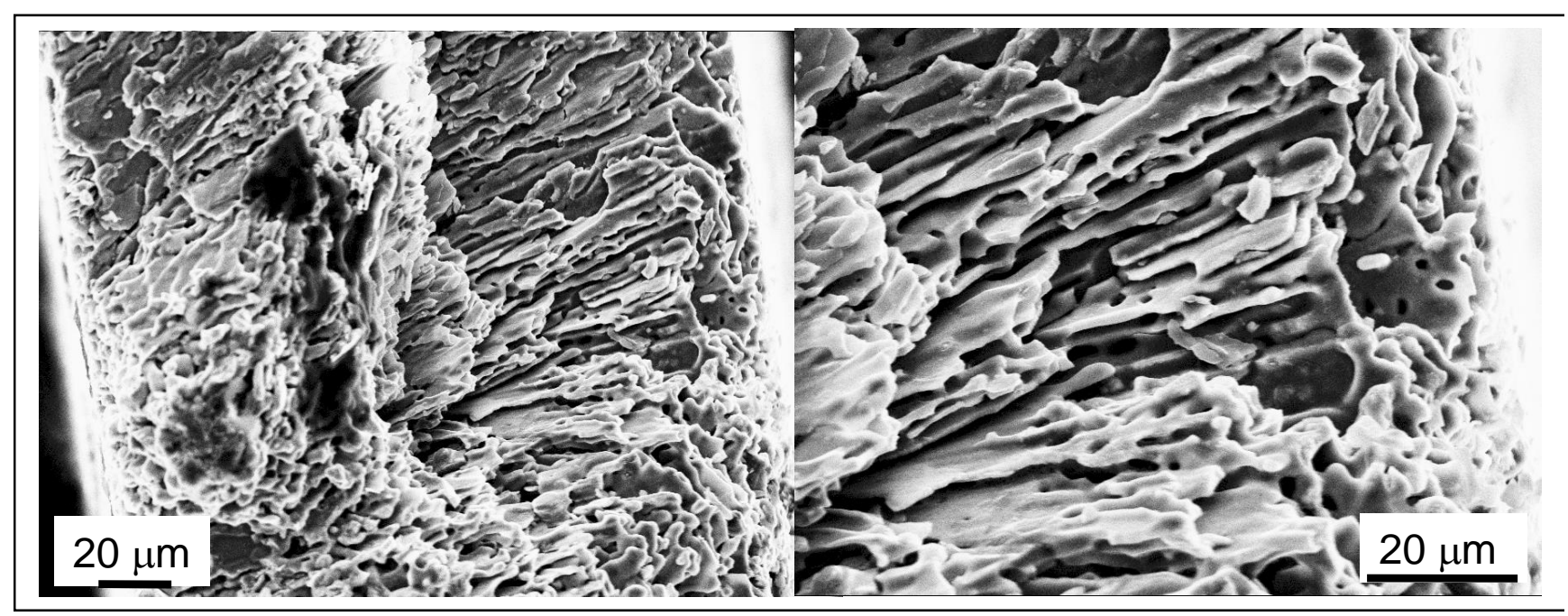


Fig. 5. SEM image of the air side of the $\mathrm{Au}_{42} \mathrm{Cu}_{29} \mathrm{Ti}_{8} \mathrm{Si}_{21}$ ribbon after dealloying with the potentiostatic method at $1.90 \mathrm{~V}$ (left). Higher magnification image on the right.

Fig. 5

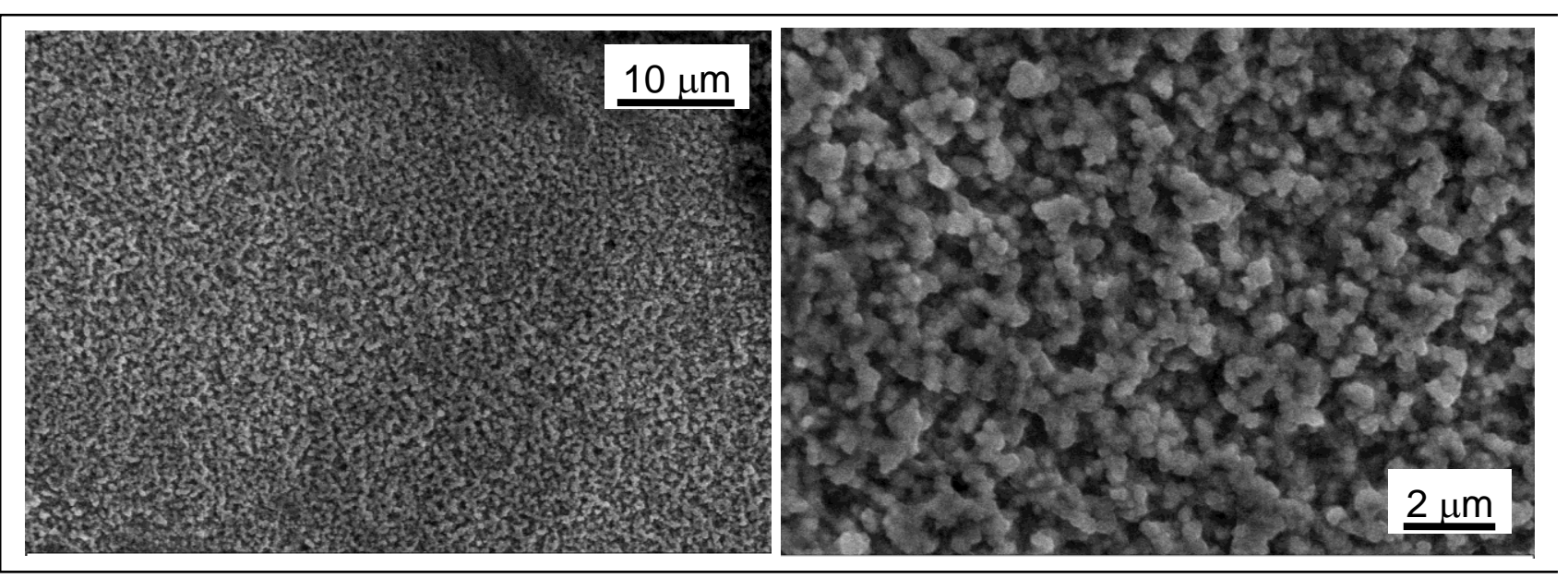

Fig. 6. SEM image of the on the wheel-side of the $\mathrm{Au}_{42} \mathrm{Cu}_{29} \mathrm{Ti}_{8} \mathrm{Si}_{21}$ ribbon after dealloying with the potentiostatic method at $1.90 \mathrm{~V}$. Porous gold with longitudinal hillocks and isolated channels. 
Fig. 6

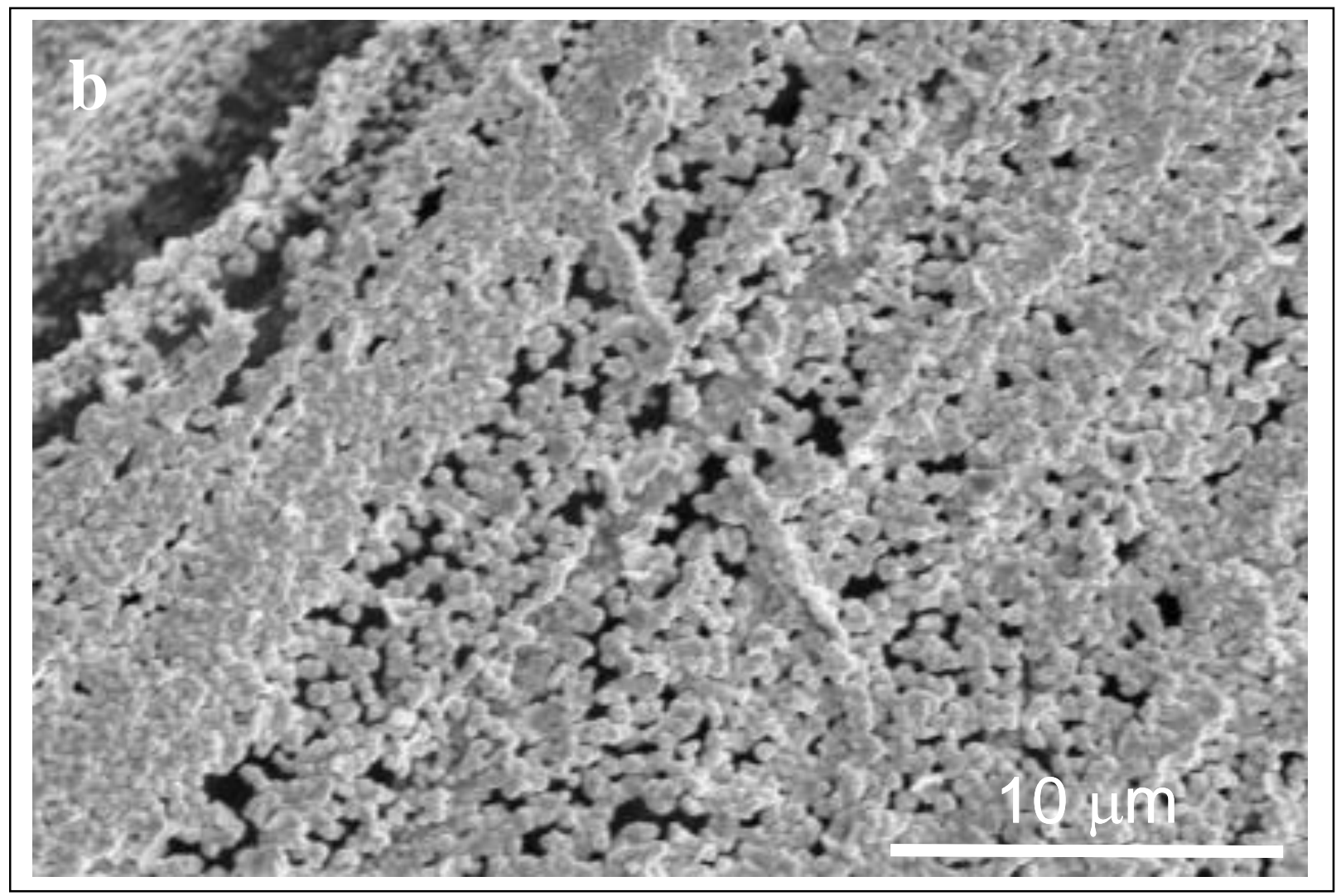

Fig. 7. SEM image of the on the wheel-side of the $\mathrm{Au}_{42} \mathrm{Cu}_{29} \mathrm{Ti}_{8} \mathrm{Si}_{21}$ ribbon after dealloying with the potentiostatic method at $1.80 \mathrm{~V}$. Corrosion cracks and Au islands. 
Fig. 7

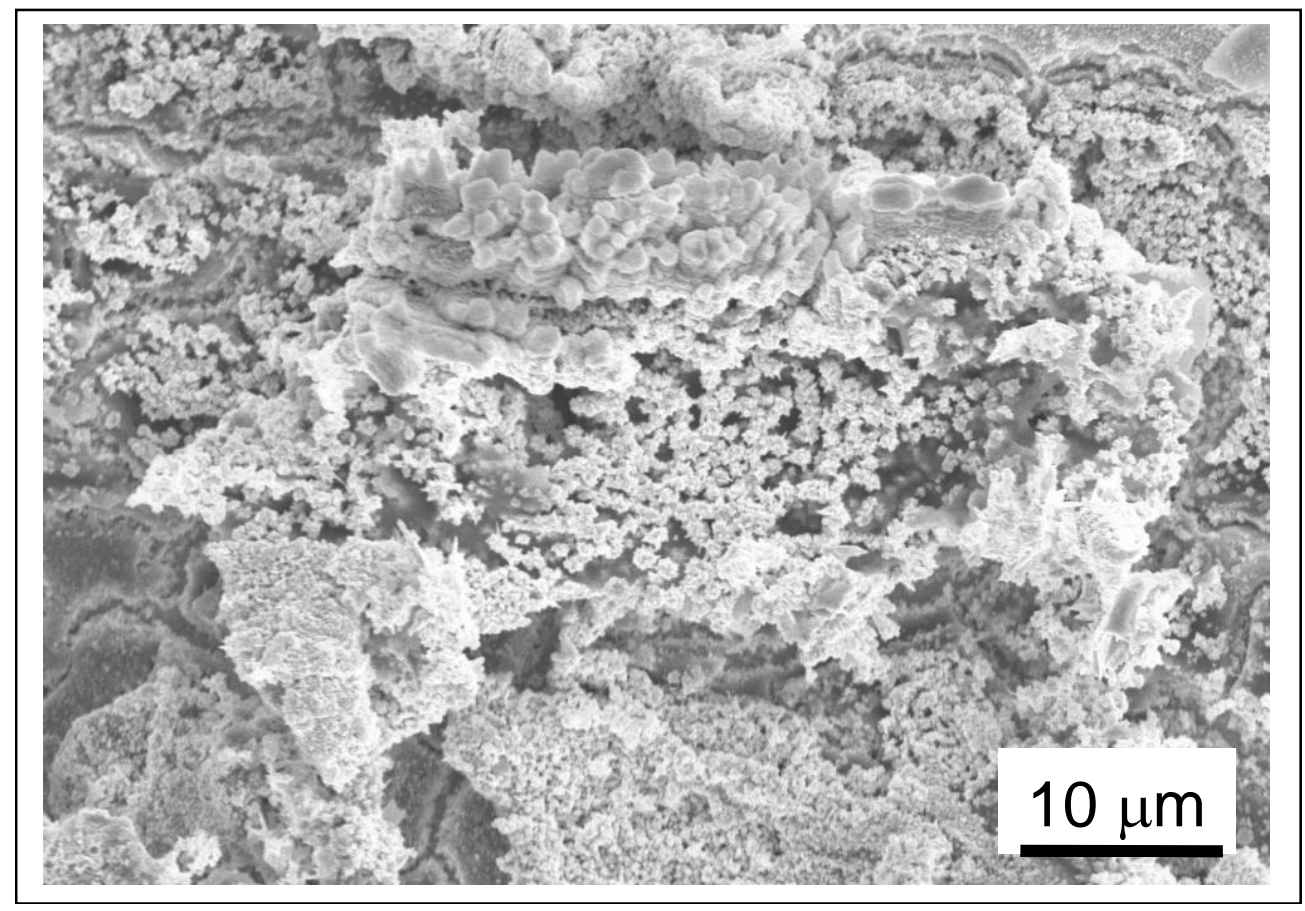

Fig. 8. Magnification of part of Fig. 7 showing corrosion cracks and locally re-deposited Au.

Fig. 8

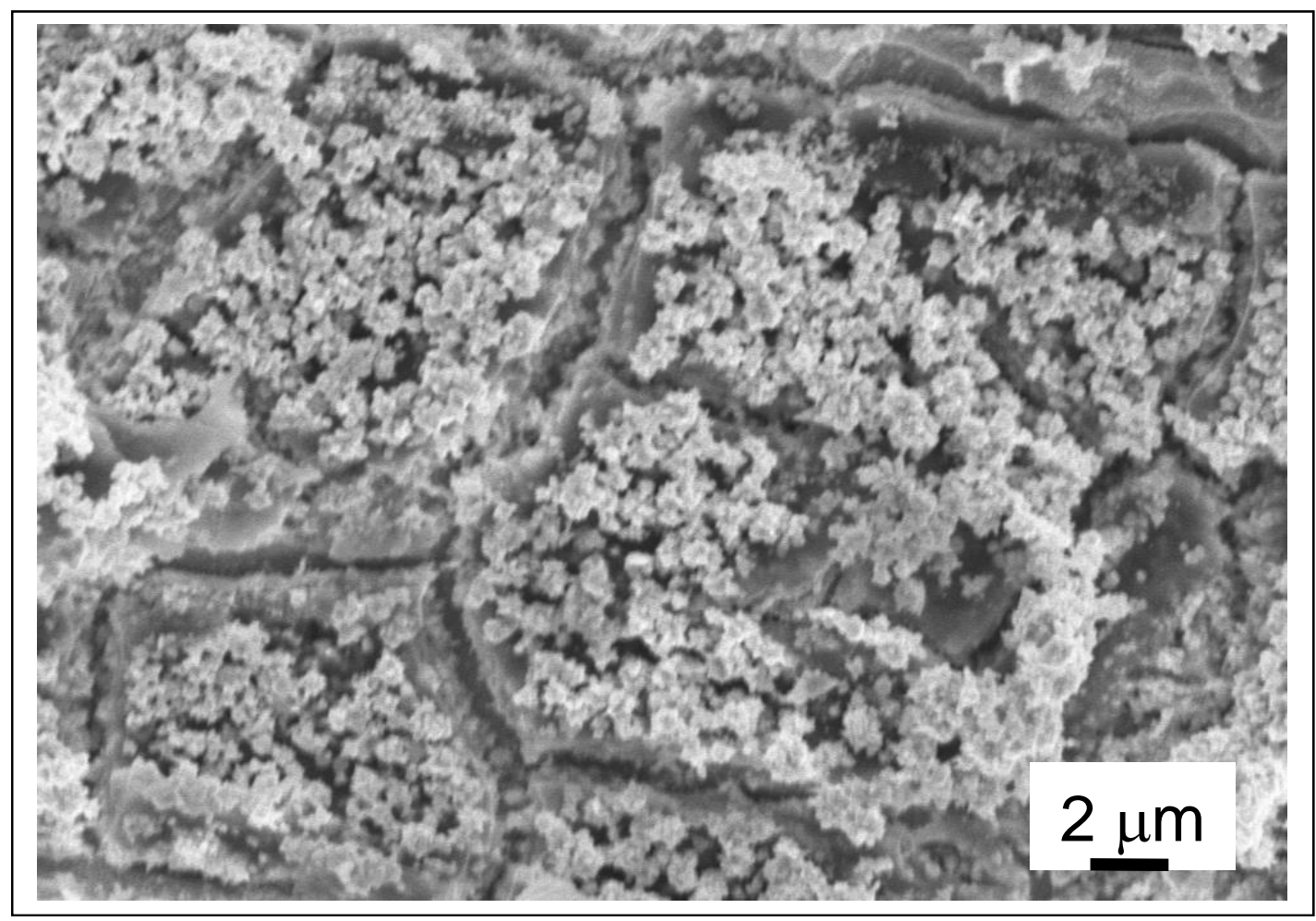

Fig. 9. Magnification of part of Fig. 7 showing re-deposited Au in layer form. 
Fig. 9

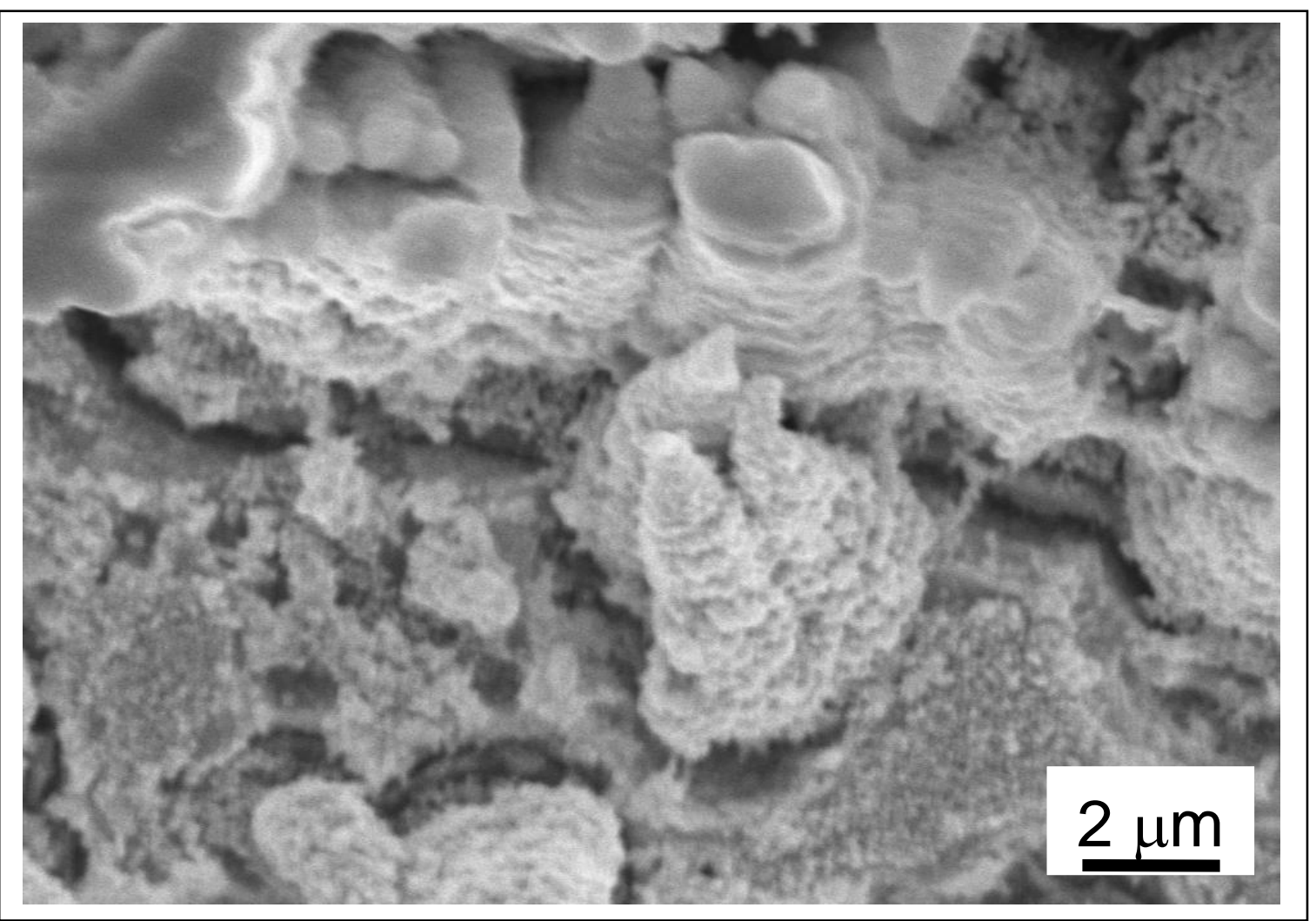

